\title{
Las "Holdings" o Compañías Tenedoras
}

\author{
Por ENRIQUE PARDO DEL ALCAZAR.
}

El presente artículo, extracto de una tesis del señor Enrique Pardo del Alcázar, constituye un interesante aporte al estudio del debatido problema de las "holding companies".

Por sus peculiares características de organización y funcionamiento, las "holding companies" -que en su aspecto puramente económico son aceptadas casi sin reservas - han sido objeto de encendidos debates al abordarse su estudio desde el pun. to de vista estrictamente jurídico.

El señor Pardo del Alcázar ha enfocado debidamente ambos extremos del problema, desarrollándolo con la hondura y claridad que dan el sólido conocimiento de la materia tratada. Trabajos como éste, reveladores de. un encomiable esfuerzo de investigación, merecen nuestro franco aplauso, sien.. do de esperar que pronto otros ofrezcan la misma calidad.

\section{UNION DE SOCIEDADES Y EMPRESAS}

Cuando las empresas o sociedades advierten las'ventajas que les reporta una acción común en sus métodos de labor, recurren a fusiones o uniones.

En la industria moderna la especialización y la división del trabajo mental, que ha llegado a términos inconcebibles hacen unos años, dan a la empresa grandes ventajas insuperables, sobre las pequeñas. Los Departamen. tos de Organización Científica del Trabajo, los Departamentos de Planes y Proyectos (Planning and Routing Department) que señalan las tareas precisas que debe desempeñar cada hombre y que al mismo tiempo coordinan toda la actividad de la empresa, llevándola a la super_eficiencia, no pueden ser sostenidos por las pequeñas sociedades o empresas. $Y$ en determinados tipos de empresas o industrias, en las que se hacen necesarios los grandes laboratorios de experimentación, invirtiéndose ingentes sumas, y para que 
estas reditúen, en muchos casos, pasarán años. Así los Departamentos de Investigación Científica del gran Sindicato de Medicinas alemán, mundialmente conocido bajo la marca de "Bayer", exigía para que un medicamento fuese lanzado al mercado, después de descubierto, un período de experimentación - mínimo- de dos años para poder determinar con absoluta precisión todas las consecuencias posibles del medicamento. Es de suponerse que este largo proceso demandase varios miles de marcos, y que para invertirlos, a veces con un gran porcentaje de posibilidades de perder, se requiriese del gran capital. De esta clase de resistencia económica, dice el famoso economista inglés Marshall (uno de los fundadores de la'Escuela Económica de Cambridge) en su obra "Industria y Comercio", "está tan lejos de alcance de un hombre de recursos moderados como lo está la planta que se requiere para fabricar planchas blindadas".

Los modernos economistas están acordes, desde la gran experiencia de la pasada Gran Guerra y de la que acaba de terminar, en las ventajas de la gran empresa que permite - como lo expresa D. H. Robertson en su obra "Industria"- "separar los problemas de técnica de los problemas de finanzas, tratar en gran escala con los compradores y vendedores, agencias de transportes y bancos, tener libertad para batir las alas y explorar vastos ho. rizontes y para acariciar sagaces designios, nobles elementos y mentes, todas estas son y serán poderosas armas en la lucha con los competidores".

Sin embargo, sería un grave error suponer las ventajas de las grandes plantas industriales, puesto que en la mayoría de las industrias, verbigracia: las plantas de producción eléctrica en los países americanos y del mundo en general, la conveniencia le fija un limite muy preciso al crecimiento de la planta productora individual; para ser eficiente una fábrica de artículos de algodón o de cerraduras tiene que ser grande, más no necesitan NI DEBEN ser gigantescas. Pero la magnitud de la empresa no se limita por la magnitud de la planta; y la unidad industrial tipica de hoy es una empresa que posee no una sola fábrica gigante, sino cierto número de fábricas de tamaño considerable, pero no enorme, cercanas tal vez unas de otras, pero esparcidas por el territorio de un país, o, mejor aún, de todo el mundo. Tal es el caso de la "Levadura Fleischman", entre otros.

Lo que hemos venido diciendo de las industrias puede y debe decirse de las sociedades de indole puramente comercial, y como ejemplo, en nuestro medio, podemos nombrar a la Compañia W. R. Grace \& C.. S. A., la que es propietaria de diversas organizaciones o empresas, delimitadas y ordenadas dentro de las reglas de la mejor técnica, de las que podríamos nombrar: Cartavio y Paramonga (azucareras), las diversas empresas productoras de productos textiles; Fábrica de Paramonga; Panagra y Grace Line (ambas de transportes); y a la Peruvian Corporation que controla casi todos los ferrocarriles del Perú, a través de compañias subordinadas como son: Ferrocarril Central del Perú, Ferrocarriles del Sur del Perú, Ferrocarril Eléctrico, etc., etc:

Estas últimas consideraciones nos llevan a determinar que no siempre la fusión de compañías o empresas en una sola es la más conveniente, puesto que se logra en algunos casos y circunstancias sus conveniencias, disminuyendo los inconvenientes, con la unión o asociación de sociedades o empresas.

La diversidad de casos y circunstancias determinantes traen como corolario una diversidad de medios de unión según la naturaleza de producción - explotación comercial, que se determina por la ubicación, la legislación y hasta por la idiosincracia de los hombres que en ella intervienen. También 
será causa determinante de forma de asociación si la asociación se produce entre sociedades anónimas y colectivas o anónimas puras, etc., etc.

\section{II}

\section{FORMAS DE ASOCIACION DE SOCIEDADES O EMPRESAS}

Para las distintas necesidades se han adoptado distintos sistemas de asociación. En las formas de organización de las asociaciones de empresas se ha prestado atención preferencial al aspecto financiero, aunque también no se deje de lado el aspecto técnico. El grado del énfasis concedido a cada uno de estos aspectos dependerá en gran parte del tiempo que se calcule a la duración de la asociación. Una asociación pasajera, o a corto plazo, se ocupará más bien de los problemas financieros de acrecentar, y quizás de reunir en un fondo común las ganancias. Un monopolio de carácter duradero se ocupará también de aumentar las utilidades mediante la reducción de los costos de producción. Sin embargo no siempre se elige entre una y otra forma de organización desde un punto de vista completamente económico, ya que - no en todos los países los gravámenes impuestos son iguales a cada tipo de sociedad y de sociedad de las mismas, o hacen más difícil o aún imposible dar fuerza legal o carácter legal a ciertos tipos de combinaciones de sociedades. Así los factores no serán iguales, descle el punto de vista del derecho, si se organiza una asociación de empresas en Estados Unidos o en Alemania o en Inglaterra.

Dificil es clasificar con toda lógica las asociaciones de sociedades, pues sus caracteres diferenciales no tienen mayor precisión y no siempre se presentan er las mismas condiciones. Tendremos pues que proceder con la mayor precaución. El criterio que seguiremos para establecer nuestra clasificación será el de la duración en el tiempo de las asociaciones.

Muy interesante seria poder hacer un breve análisis de cada tipo de asociación, pero desgraciadamente sería extendernos en forma excesiva. Nom_ braremos pues los tipos de combinaciones más conocidas y haremos una pequeña disquisición acerca de las características comunes a cada grupo. Entremos pues al estudio de las formas de asociación:

ASOCIACIONES A CORTO PLAZO: Estos son los tipos de organización más pasajeros $y$, por tanto, menos formales. En su mayoría pueden darse por rescindidos previo aviso a corto plazo o en una fecha fija. Por lo regular no entrañan cambios en 13 organización de las compañias asociadas, ya sea en su aspecto técnico o financiero, pues se apartan de la premisa que pasado un período corto, poco más o menos, se reanudará la competencia. Aunque no se presuponga lo anterior, debe dejarse a cada empresa capacidad de retirarse y obrar indepcndientemente, siendo estas de las más importantes características de este grupo. Sus tipos más importantes son:

Compromisos informales o acuerdos de caballeros (gentlemen's agreement).-Acuerdos de productores o comerciantes, en competencia acerca de los precios o áreas de venta.

Asociaciones para la regulación de precios.-Estas significan un acuerdo formal entre productores o comerciantes que se asocian para fijar precios mínimos de venta.

Asociaciones para regular la producción.-En éstas se fija el volumen de producción de cada producto, bajo pena de multa en caso de excederse. 
Asociaciones para formar un fondo común.-El tipo más simple es el de que cada empresa-miembro dé su cuota para el fondo común, el que periódicamente se repartirá después de dejar alguna reserva. Un arreglo más complicado es el que fija a cada asociado un porcentaje de la producción total con las consiguientes multas, etc., etc.

Asociaciones de distribución de contratos.-Se encuentran éstas en ciertas industrias en que se asignan los contratos según las ofertas que hagan las diversas empresas-miembros. El consorcio determina a qué sociedad o compañia le corresponde el contrato estando en el acuerdo que ninguna de las demás compañias lo pueda tomar. En algunos casos se distribuyen las zonas o mercados.

En las formas enumeradas no se altera la organización interna de cada sociedad. Estas conservan no sólo. su independencia técnica y financiera sino también sus personales de ventas $y$, compras. Así pues, la característica fundamental de estas asociaciones de poca duración eš que no se altera la estructura de la competencia en la industria. Esto superpone a ella alguna organización central que limita la concurrencia.

FORMAS TRANSITORIAS.--"Entre las organizaciones a corto pla. zo de duración limitada y las formas de organización a largo plazo se encuentra un grupo que se distingue por su carácter transitorio, si bien a veces es de larga duración". Dentro de este grupo las asociadas se conservan fundamentalmente independientes; conservan su identidad financiera y técnica. Dentro de la asociación existen conflictos que se manifiestan de cuando en cuando en la desintegración de la cohesión; pero cada empresa o sociedad sacrifica cierta parte de su estructura de competencia, por lo general su organización individual de ventas, y se ponen tocias de acuerdo en este aspecto de sus funciones.

Regularmente ocurre que este grupo de asociaciones es de carácter transitorio, es decir una forma de organización media entre la competencia y la consolidación final. Pero en ocasiones perdura, especialmente en Alemania, ya que la experiencia ha demostrado que el consorcio de breve duración, en el cual se toma parte sin contrato que tenga fuerza legal, resulta sumamente inestable. En Alemania, gracias a la idiosincracia de su raza y al apoyo de la ley, estas organizaciones han tenido mucho éxito, y el auge financiero-técnico del sistema económico propiciado por el Dr. H. Schacht en el régimen del Nacional-Socialismo se debió a que tal organización fué fundamentalmente el perfeccionamiento de la aplicación de los principios cartelianos. En Estados Unidos por lo regular no han tenido fuerza legal estos contratos, llegando a ser ilegales, no habiendo tenido éxito por estas circunstancias. Los tipos más importantes son los que siguen:

Las agencias de venta.-Cierto número de empresas que fabrican los mismos articulos se comprometen a remitir su producción a una agencia de ventas común, con el objeto de evitar la competencia ruinosa. No es necesaria la regulación de la producción.

Cartel de participación con agencias de ventas.-Este tipo fué creado en Alemania y es donde más ha sido adoptado en diversas industrias. Los productores acuerdan establecer, por un período determinado, una agencia exclusiva para la venta de sus productos y se adjudica a cada productor una proporción en la producción total. Los que excedan su participación pagan una cuota, los que producen menos de lo que les corresponde reciben una participación o compensación. La agencia de ventas es una sociedad anónima, donde los accionistas son los productores asociados, teniendo cada uno 
de elloz un número determinado de acciones de acuerdo con su porcentaje de producción. Los asociados fijan un precio de costo básico para sus productos, y venden a la agencia a un precio contable superior al del costo.

La agencia venderá en el mercado al mayor precio que pueda obtener, aunque no acostumbra vender a un precio mayor que el contable.

Asociación financiera de intereses (Interessengemeinschaft).-Se establece ésta cuando dos o más empresas convienen por cierto número de años (en algunos casos hasta cincuenta), en reunir en un fondo común la totalidad de las ganancias de sus miembros y repartirlas en proporciones determinadas de antemano. Teóricamente, esta organización o asociación es de carácter transitorio y cada compañía conserva su existencia propia y administración independiente; pero ocurre que trabajan en forma muy estrecha mediante las comisiones mixtas. La experiencia demuestra que tienden y forman un consorcio más completo. Los dos ejemplos más conocidos en el mundo son el de la I. G. Farben (alemana) y el de la Imperial Chemical In. dustries (británica).

ASOCIACION DE SOCIEDADES DE LARGA DURACION. - Es difícil precisar los límites exactos entre los diversos tipos que componen el grupo de las formas transitorias que acabamos de estudiar con los de larga duración. Además, como antes lo manifestamos, muchas de las formas transitorias han tenido vida por más de 50 años. La pauta diferencial más importante consiste en el grado que sobrevive la estructura de competencia e independencia de las compañías o empresas. Hecha la salvedad, indicaremos las formas más importantes de larga duración, que son:

El fideicomiso de votos (Trust o Volting Trust).-Este procedimiento de asociación de sociedades prevaleció en los Estados Unidos por algún tiempo hasta ser declarado ilegal por la Corte Suprema. Cierto número de Compañías acordaban traspasar el total de sus acciones a un grupo de fideicomisarios, recibiendo a cambio de ellas certificados de fideicomiso por su valor. Así los fideicomisarios quedaban capacitados para controlar completa. mente la dirección de los negocios de un grupo de empresas. Teóricamente la asociación era permanente. El ejemplo típico es el de la Standard Oil Company. En la actualidad se dá el nombre de Trust a las asociaciones que más bien merecen el nombre cle "Intercambio de Acciones" u "Holdings".

Intercambio de acciones.-Dos o mas compañias pueden enlazar su suerte con el intercambio de acciones. Los resultados dependen de la magnitud de las empresas y del número y proporción de las acciones intercambiadas. Cuando predomina una empresa en cuanto a volumen y adquiere una mayoría de acciones. la otra es virtualmente una subsidiaria, y bien puede tener voz y voto en la dirección de la empresa más grande. En algunos casos se crea el intercambio para dar una mayor estabilidad a las asociadas, o a los accionistas de las compañias que se asocian, pero casi siempre se constituyen con el fin de llegar a las otras dos formas: "Compañía Tenedora" (Holding Company o Trust Holding) o a la Consolidación o Fusión. De la pris mera forma, la Holding Company, nos ocuparemos en forma más extensa a través de los capítulos siguientes. La Fusión o Consolidación no requiere explicación, por ser la unión, que como el propio nombre lo dice, absorbe la identidad de las asociadas, en beneficio de una. de ellas. 


\section{III}

\section{LAS HOLDING COMPANIES}

La Holding Company, también conocida con el nombre de Holding Trust, y en castellano como Compañía Tenedora $u$ Holding, se constituye para adquirir el control de otras compañías, ya sea adquiriendo una mayoria de acciones o adquiriendo el número de "acciones preferenciales" suficiente para tener la mayoría de votos en su poder; recibiendo en cambio los accionistas de las compañías primitivas acciones de la Compañía Tenedora u Hold_ ing Trust. Puede también la Holding Company adquirir propiedades, o sean fábricas, negocios, minas, etc.

Las Holding Companies intégranse regularmente para obtener el control mono-político de una actividad, o para llegar a dominar en forma completa $\rightarrow$ o sea desde su fuente de materias primas hasta la venta al comer cio- la de una industria. Luego podrá integrarse, en el primer caso, en forma horizontal, verbigracia: un Holding destinado a controlar el reparto de la leche en una gran capital, o de la producción de artículos de farmacia, como la I. G. Farben de Alemania o integrarse verticalmente, o sea adquirir minas, haciendas, barcos, fábricas y refinerías, como es o fué. la Standard Oil de New Jersey, que controlaba los campos petrolíferos, la producción de maquinaria para estos campos, los barcos-tanques para transporte del petróleo y sus derivados, las plantas de refinación de petróleo que trataban: gasolina, kerosene, aceites diesel, alquitrán. asfaltitas, etc.; y por último hasta los laboratorios de insecticidas o artículos de ese género.

La diferenciación de un tipo de integración con el otro én forma preci_ sa es muy difícil, pues dada la complejidad de sus funciones y la amplitud de sus aspiraciones, regularmente los limites se entrecruzan.

Esta forma de asociación de empresas es, con mucho, la más corriente. en la actualidad, de todas las asociaciones de larga duración. Conserva la existencia individual de cada empresa, la que disfrutará de un mayor o menor grado de autonomía, o sea que se retiene cierta flexibilidad y la ventaja de la responsabilidad limitada de sus componentes, y al mismo tiempo hace posible la coordinación en asuntos esenciales, subordinando los intereses de cada empresa a los del grupo. "Durante algún tiempo se empleó extensamente en los Estados Unidos".

"La Standard Oil of New Jersey era una compañía tenedora que controlaba a las compañías Standard Oil de diversos estados norteamericanos. En los años más recientes han sido las pirámides de compañías tenedoras edificadas por el ingenio de financieros como Samuel Insull y los Van Chweringen. También en Gran Bretaña se ha recurrido a la Holding Company con bastante frecuencia". (Monopolio.-E. A. G. Robinson). En la América del Sur se han desarrollado especialmente en la Argentina, donde las Compañías Tenedoras controlan el reparto de la leche en Buenos Aires y la producción de energía eléctrica de la mayor parte del territorio argentino. Nombres famosos en la industria y el comercio del mundo, como son: United Steel Companies, United Shoe Machinery, la Vickers, en numerosas secciones de industria armamentística, aeronáutica y siderúrgica en general, la David Colville, Du Pont de Nemours Co., International Nickel Co., Eastman Ko_ dak Co., Imperial Chemical Industries entre las más importantes de las an- 
glo-americanas y entre las alemanas tenemos, Siemens Chukert Concerns, Siemens Chukert und Halske, Elektrisitats A. G., etc. Larga ha sido la lista, pero interminable sería el proseguir nombrando sólo las multimillonarias y mundiales; su enumeración sería la de las grandes empresas del mundo, sin escaparse a su influencia: el acero, minas, petróleos, ferrocarriles, compañías de aeronavegación y de, aviación, de navegación marítima y fluvial, de transportes terrestres, de automóviles, productos químicos, etc., etc.

La Holding Company es una forma de organización menos compleja que las anteriores (Trust y Cartel) dá lugar a economías que no le són asequibles a un cartel y tiene una base más permanente y unida. Además es fácil de constituír, ya que lo único que exige es un traspaso de acciones.

Mediante este recurso, un número reducido de personas (naturales) por medio de una sola sociedad (única persona jurídica) puede controlar mucho más capital del que posee. Tomemos un sencillo ejemplo hipotético: supongamos que dicho grupo de personas posee un poco más de un millón de libras en acciones, lo que le permite ejercer el control de la Compañía "A", que tiene un capital social de 4 millones de libras, mitad en acciones, mitad en obligaciones preferentes (los tenedores de las acciones preferentes no ejercen ningún control). La Compañía " $B$ " adquicre una mayoría de acciones de la Compañía " $C$ " que tiene un capital social de 8 millones, mitad en acciones comunes, mitad en obligaciones preferenciales. La Compañía " $C$ ", adquiere una mayoría de la Compañía "D" que tiene 16 millones; y así sucesivamente. Cuando ocurre esto, los intereses de los accionistas minoritarios (que en realidad son mayoría), en las empresas subsidiarias, peligran puesto que ya no pertenecen al grupo que ejerce el control. A veces se le concede a las compañías subsidiarias bastante libertad de acción, pero el grupo de compañías, constituye en esencia, una sola empresa cuya política depende directamente del grupo que ejerce el control, en nuestro ejemplo, de los que controlen a la Sociedad "A". Ahora bien, si los intereses de los accionistas minoritarios chocan con los de ese grupo, serán los de aquéllos los que sufran.

En la magia de la Holding Company, los propietarios de un millón y una libra (acciones de la Sociedad " $A$ ") formarán mayoría omnipotente en las Compañías "A" de dos millones; "B" de cuatro millones; "C" de ocho millones; "D" de dieciseis millones (según nuestro ejemplo: Benham). Por tanto un millón y una libra serán - para los efectos legales y de controlmayoría sobre 28.999 .999 libras.

La Holding Company es, pues, una forma muy hábil de controlar enormes intereses industriales sin parecerlo. Gráficamente se le podria representar como un gigantesco pulpo cuyos tentáculos de monopolio ahogan toda competencia reteniendo un mercado específico.

La organización es muy difícil de atacar, por razón de la aparente independencia y autonomía que tienen las firmas industriales que la componen. Este ha sido uno de los obstáculos más poderosos que han encontrado los legisladores en lo que concierne a su independencia y vigilancia legal.

Ahora concretaremos algunos puntos importantes de las Holding Companies que no han sido precisados en los párrafos anteriores.

En primer término, es el instrumento ideal para la formación de este tipo de sindicato económico (Combination); pues basta substituir las acciones de las empresas por fusionarse por las de la nueva compañía; o bien, adquirir las acciones de las empresas que en lo sucesivo serán controladas por la Tenedora. Además, dentro de los tipos de compañías, la sociedad anónima es la más susceptible para encaminar según los fines necesarios. 
También es importante, y en algunos casos de vital interés, la acción preferencial con pluralidad de votos, puesto que es el ideal vehículo para conseguir el control de una sociedad anónima con una mínima inversión condicionada a la voluntad de los contratantes.

Por otra parte, hay que tener en cuenta que nada obstaculice a la Holding Company para que, junto con su función de tenedora, pueda dedicarse a cualquier actividad económica permitida.

Además conviene precisar que la finalidad de las Holding Companies no es solamente la adquisición de acciones de empresas - aunque se integren, en sentido monopolistico- y de los beneficios que resulten por la posesión de las msimas, y es la gran administradora, siendo coordinadora - por ende reguladora - para asegurar el mayor rendimiento mediante la racionaliza. ción de los esfuerzos en forma mancomunada. Si la Compañía Tenedora Holding Company - se concretase a la posesión y disfrute de valores mobiliarios con fines de lucro con un sentido inversionista, se denominarian de omniun, y también Compañías Inversionistas, etc., etc.

También es sumamente importante insistir que la "Holding" no es una fusión de empresas, sino la subordinación y unión de sociedades que permanecen autónomas, conservando su individualidad económica y jurídica.

Es interesante hacer resaltar, cosa que ya se ha visto, que para el desarrollo de la Holding Company no hay limitaciones, puesto que así como abarca empresas puede abarcar grupos de empresas o sindicatos, los que constituirian las sub-Holdings, formando un verdadero sindicato o asociación económica dependiente $y$ asociada. Puede tenerse, entonces, una Holding Company principal y un número variable de sub_Holdings, lo que no se opone a la asociación de otras empresas directamente a la Holding principal.

\section{IV}

\section{VENTAJAS E INCONVENIENTES DE LAS HOLDING COMPANIES}

Los problemas en el campo económico moderno son sumamente complejos, pues no pueden desintegrarse y llegar a unidades, como serian: técnica, comercio, industria, financiación, capitales, etc., pero todos giran, especialmente dentro del aspécto resolutivo alrededor del capital y la forma de su financiación. Pongamos por caso la industria minera, la que tiene problemas de carácter técnico-minero, como el caso del descubrimiento de la mina; estudio para su explotación: cubicación, análisis, etc., etc.; estudio de los sistemas de recuperación; estudio para las instalaciones de plantas de explotación, de energía, etc.; por último hasta estudio del capital que debe necesi-: tarse (aspecto interesantisimo, descuidado en nuestro med:o y al que se deben grandes fracasos de nuestros rudimentarios mineros). Comerciales - cotización del mineral, mercados, aspecto bolsistico, etc. Financiación de los Capitales. Como se podrá ver en esta pequeña enumeración de problemas que se presentan para la organización de una Compañía Minera, sin el factor capital no cabe el desarrollo de la industria moderna. Repetimos que esa industria minera, como cualquier otra industria, no empirismo minero en el que se pone todo en manos de la suerte, sino en la industria cargada de técnica y técnicos indispensables, la única vía positiva para la solución de los proble. mas - cuando éstos pueden ser resueltos- es la del capital que proporciona los medios eficientes, humanamente hablando. 
De este aspecto nos hemos ocupado en el Capítulo I de este trabajo y a través de todo él hemos visto la importancia y casi necesidad de la gran sociedad o asociación plena de recursos de todo orden, y esto lo estamos viendo en la vida económica diaria de nuestra patria, la que ha ido adquiriendo cada vez ritmos más modernos, más capitalistas, y así hemos visto las grandes sociedades agrícolas, como "Casa Grande" absorbiendo a todas las compañías o agricultores vecinos que no han podido resistir la agonía de las diversas crisis por las que ha pasado nuestra industria azucarera, a la que ha resistido victoriosamente "Casa Grande" por las facilidades que le daba su poderío y grandeza económica, los que le conseguían menores costos de producción, una mejor organización debida "a un estado mayor" o "planning department", mejores condiciones para sus fletes, costos más bajos en las operaciones portuarias por tener una instalación de esta índole completa en Puerto Chicama, etc., etc.

Por todo lo expuesto llegamos a la conclusión que en la industria moderna, para su desarrollo y vida, un factor primordial es el gran capital, y una de las mejores formas de concentrar el capital, tanto desde el punto de vista positivo, o sea del capital y reservas mismas, cuanto del negativo, o sea el capital a conseguirse. por los créditos, más fáciles de conseguir para la gran organización.

Después de ver las ventajas en forma global, vamos a tratar de señalar las ventajas que trae consigo la Holding Company en el campo económico de un país, las que son:

Facilidades de obtener capitales.-En los grandes centros financieros Londres, New York, Chicago, Amberes, etc.,- las empresas de pequeñas proporciones en la práctica, no tienen acceso; luego no podrán adquirir los capitales que necesitan para su expansión, y en el difícil supuesto de lo_ grarlos, tendrian que pagar por ellos elevados tipos de interés, grandes gastos generales para la colocación del empréstito por falta de las necesarias vinculaciones - viajes de los Directores, estadías de los mismos, etc. - Siendo así que el mismo empréstito, sin mayores gravámenes, hubiera sido colocado por la gran Compañia por intermedio de corresponsales o aún utilizando vías directas: cables, teléfonos, etc., etc. Así, una gran empresa que necesitase S/o. 20'000,000.00 no será tenida en cuenta en la Bolsa de Comercio de New York o Londres; en cambio si pertenece a una Holding Company poderosa. hallará con facilidad el dinero requerido y aún interés moderado. En esos grandes mercados a una compañía desconocida nadie le hubiera prestado, pero el préstamo se ha facilitado por el respaldo que representa la Holding Company de la que forma parte.

Es un principio básico de Economía Politica, que la tasa del interés varia de acuerdo con la garantía moral o material que ofrece el prestatario, y este principio no sólo funciona en los grandes mercados sino en todas partes y todo tiempo. Sin ir más lejos, puede averiguarse los tipos de interés que cobran los Bancos de Lima a Milne \& C. S. A., International Petroleum Co. Ltd., Sociedad Agrícola Chicama S. A. y Grace \& Co. S. A. y los que cobrará a Federico García o Miguel Polo, si es que el Banco, el mismo que lucha por conseguir hacer de prestamista de una de esas grandes empresas, se digna prestarle a García o a Polo. Es pues incuestionable la distinta con* fianza que inspira la Holding Company, asociación de muchas compañias, casi por fuerza millonaria, frente al de una de las compañias individual e independientemente consideradas.

Por último, la misma Holding . Company podrá facilitar los préstamos utilizando parte de sus propias reservas. Sin duda alguna percibirá un ré- 
dito, pero siempre menor y más ventajoso para la prestataria, quien indirec: tamente se beneficiará en cierta forma con el mismo producto obtenido al préstamo.

También podrá hacer, por medio de lo que en la costumbre bancaria se llama re-descuento, un re-préstamo. Asi la empresa $X$, independientemente hubiera logrado en New York un préstamo con un tipo de interés del $8 \%$. Por intermedio de la Holding Company obtendrá al 5\%. Seguramente la Holding también se beneficia pues a ella sólo le costará el 3 o $4 \%$, cobrando una retribución por su función de proveedora de capitales. De cualquier for... ma ha existido una real economía para la Compañia $X$, la que directamente le representa una economia del $3 \%$ anual sobre el capital conseguido en calidad de préstamo.

Muchos de los maravillosos adelantos y comodidades, puestos al alcance de todos, sólo se han podido obtener gracias a la magia poderosa y multiplicadora de las Holding Companies.

Facilidades de orden técnicc. También en el Capítulo I de este trabajo hablamos de los maravillosos métodos de organización de los laboratorio de investigación que poseen las grandes empresas, en los que se invierten enorme sumas con gran generosidad y sin miras a obtener un lucro inmediato, y citábamos el ejemplo de la I. G. Farben, y como este ejemplo podemos citar el de la Dupont de Nemours. a la que se deben tantos adelantos de orden técnico y que han resultado benéficos para la humanidad. Lo mismo puede decirse de los inventos realizados a través de los grandes laboratorios experimentales de las Holding Companies, como: Standard Oil of New Jersey, Imperial Chemical Industries, etc., y en otros campos. no se podría suponer que hoy fueran realidades los sueños de Verne, como las actuales líneas de aeronavegación que circundarn los continentes, las cuales para establecerlas han sido necesarios gastos de millones en la organización complicadísima de las rutas del aire. Todo esto, producto de unos cortísimos años, hubiera sido imposible de realizarse de no mediar la concentración. la asociación de compañía: las Holding Companies.

$\mathrm{Y}$ al hablar de las Holding Companies en su contribución al progreso y comodidad de la Humaniclad. no debemos olviclar los elementos que la definen: vida de las compañias o empresas asociadas dentro de una coordinación. Esta forma de conjugar la inciependencia con la unión. ha brindado las grandes facilidades que representan obtener para una misma compañia o empresa, ya sea comercial o industrial o mixta, las ventajas de la gran Compañía y las ventajas de la pequeña compañía; el gran capital sin ahogar la vida independiente plena de iniciativas que se angostarían de otra forma:

Racionalización de la producción.-Por distintas causas, que trataremos de enumerar, las Holding Companies pueden organizar mejor su producción, circunstancia que le permite reducir sus costos de producción, o de los servicios prestados. De estas causas las más saltantes son:

a).-Organizar sus agencias de compras, las que adquirirán en proporciones muy superiores a las que podrían hacerlo las Compañias independientemente, consiguiendo, por ende, mejores precios, facilidades $\mathbf{y}$ en conjunto mejores condiciones por el interés que tiene que despertar entre los proveedores el gran volumen de compras. También, y no es extraño según el tipo de organización, que la Holding Company adquiera los artículos que necesite determinada de sus compañías subsidiarias de otra que pertenezca a su misma agrupación, con las ventajas consiguientes para ambas, pues, en el supuesto de carestía de la materia requerida, se tendrá que dar la prefe- 
rencia a la Compañía que pertenezca a la misma organización, por razones de propia conveniencia que son obvias; y en el caso de super-producción, o sea el inverso del ejemplo antes propuesto, se repetirá el mismo fenómeno pero en orden opuesto.

b).-Las posibilidades que existen para la Holding Company para preparar un gran departamento de racionalización de la producción y el trabajo (Departamento Científico y Planning Department) que colabora en la producción de todas y cada una de las empresas asociadas. Estos departamentos son eficientísimos y de gran importancia ya sea en la industria o en el comercio, pues mientras que en la industria se podrá tener y propor cionar los grandes técnicos y científicos, la Holding Company de empresas comerciales o de servicios podrá proporcionar sus abogados, contadores, vendedores, compradores, sus servicios de informaciones, sus cuerpos consulti vos $y$ financieros super_especializados y eficientes. Todos estos servicios, y los demás que se podrían prestar, cuestan ingentes sumas, imposibles de solventar por lo regular por empresas particulares, y otras veces pudiendo pagarlo les será no-económico. En cambio la Holding Company podrá pagar y dar ocupación racional a estas personas especializadas y de alta capacidad y eficiencia, servicios que serán facilitados a cada una de las empresas asociadas.

c).-La coordinación del trabajo en las distintas empresas asociadas produce los consiguientes beneficios, tales como un menor costo, obtener una mayor y mejor producción, funcionando así el tan querido principio he. dónico: "Máximo rendimiento con mínimo esfuerzo".

d).-Facilidades a óbtenerse en casi todos los órdenes, por su ma. yor poderio, las que repercutirán en forma directa sobre los costos y tendremos materia prima barata, baratos servicios especializados, baratos transportes, estabilidad económica (de la que a continuación hemos de tratar).

Estabilidad económica.-La variedad de actividades y las distintas ubicaciones y peculariedades de cada empresa, harán distribuir y reforzar las fuerzas para soportar los embates de las crisis. También, y es de suma importancia tenerlo presente, las Holding Companies están mas preparadas para luchar contra la especulación y para romper la línea de especuladores que en propio beneficio y en desmedro del gran público y del productor, multiplican los precios a medida que van pasando por los canales que ellos dirigen. Típico ejemplo del éxito en combatir la especulación por intermedio de la coordinación de empresas industriales o de comercio; lo tenemos en la forma que para crear un comercio e industria próspera en Alemania sirvieron los sistemas impuestos a iniciativa del gran economista D. H. Schacht, en el año de 1935, produciéndose el milagro de disminuir los precios para el público y mejorarlo para los productores, asegurar la vida a los comerciantes y matar la desocupación, terrible problema que tenía sobre una población total de 70 millones de habitantes de los cuales eran 10 millones desocupados. El ejemplo alemán, con las necesarias variantes y acondicionamientos, dadas las distintas calidades de pueblos y hombres, fué implantado en los Estados Unidos de Norte América por el Presidente F. D. Roosevelt dentro de los lineamientos del "New Deal".

A pesar de tener a la mano gráficos, publicados por órganos oficiales de diversos Estados, no los uso por temor de que haya influído en su elaboración el deseo, quizá subconsciente, de propaganda.

En los tiempos de guerra que hemos vivido, desde el año de 1939 , no hemos visto otra cosa que el afán de coordinar las empresas; ya por particulares, ya por los Estados. En nuestro país las Holding Companies o semi- 
Holding Companies hacen ya varios años que funcionan; desgraciadamente circunstancias de discreción y de la pequeñez del medio me impiden citar ejemplos harto conocidos.

La abundancia de recursos y de medios particulares propios permite a las Holding Companies elegir momento y mercado para lanzar con oportunidad sus acciones, sus solicitudes de préstamos, sus ventas, etc. Al mismo tiempo podrán impedir las maniobras bursátiles destinadas a las alteraciones violentas de cotizaciones, que son peligrosas para la vida de las empresas.

Racionalización de la distribución.-Aspecto este muy importante, dado que el juego de la bolsa y de la especulación ha llevado a producir a los hombres las cosas más absurdas y lo que debió ser tiempo de abundancia se convirtió en ticmpo de miseria. Y $Y$ así tenemos que la locura del especula. dor, lo que llama el gran economista Werner Sombart, como los resultados dorados del "adelanto de los siglos XIX y XX" llevó en nuestro hemisferio, mientras en Europa y Asia morían millares de seres, a quemar 7 millones de toneladas de café en el Brasil; de exterminar a 6’200,000 cabezas de ganado porcino, botar al mar 2 millones de toneladas de arroz, botar al mar 200,000 litros de leche eilaria y sacrificar 600,000 unidades de ganado vacuno en los 3 o 4 primeros meses de 1935 en los Estados Unidos, conforme a las comunicaciones de la Oficina de Comercio de ese gran país.

También en Europa, aunque en menor escala, se ha imitado el ejemplo de destruir alimentos y productos para sostener el juego de la bolsa. En cambio los datos đe la Liga de las Naciones han registrado en los últimos años un promedio de más de 2 millones de personas muertas de hambre y frío.

$Y$ no vayáis a creer que estos crímenes se han cometido sólo cuando en el propio país sobraba. Leed los incendiarios capítulos de la famosa obra del notable escritor yanqui Steinbeck, titulada "The Grapes of Wrath", en la que se pinta con rasgos patéticos y sombríos, la tragedia de ese libertinaje económico que hacía arrojâr los alimentos por los mismos que veian morir en su derredor a los suyos de inanición.

El fenómeno descrito en los párrafos anteriores se debe a que no han existido empresas capaces de guardar sus productos cuando abundaban, para los tiempos de escasez. La vieja visión faraónica se repite, pero no hay el bíblico José que haga abrir los ojos a los dirigentes para "los tiempos de las 7 vacas flacas".

Este fenómeno de mala distribución, cque puede evitarse por las grandes compañias, es imposible de controlar por el productor aislado y siempre en frentado al intermediario. La fuerza prodigiosa de un Holding o símil, es el caso del Diamont Syndicate controlando por años, el precio del diamante en el mundo.

Las Holding Companies pueden enfrentarse con éxito a los núcleos de los intermediarios, y en casos, si las urgen, suprimirlos. Ellas pueden disponer de los grandes depósitos y elementos para poder sostener los excedentes en busca del año en que faltarán, el que no tardará en presentarse.

Mejores condiciones de trabajo.-En tesis general puede afirmarse, contra todos los postulados de la propaganda marxista del mundo, que las grandes empresas dan a sus servidores mejores condiciones que las pequeñás. En nuestro medio, con sólo estudiar los libros de reclamaciones del Departamento de Procuraduría de la Dirección del Trabajo, se puede verificar este aserto, al parecer audaz e insensato.

Salarios más elevados, tareas realizadas con mayor higiene y medidas de seguridad, almacenes para proveer a precios de costo, organización de aso- 
ciaciones con fines sociales y de asistencia, etc., etc., todo esto sólo es posible dentro de las grandes empresas, de grandes recursos y numeroso personal.

Por otra parte, no hay que olvidar que la Holding Company da a sus servidores en sus colocaciones un elemento hada despreciable: la estabilidad y permanencia de la colocación.

Las Holding Companies y el gran público (o pueblo).-Las Holding Companies han sido duramente atacadas por los marxistas llamándolas: ins. trumentos de monopolio y de aumento de precios; pero la realidad, en la gran mayoría de los casos, es otra muy distinta. Las Holding Companies, gracias a las causas enumeradas, cuentan con una serie de ventajas para producir mejor, más barato, más abundante, etc., razón por la que rompen toda com. petencia y por un lógico deseo de conservar sus utilidades, éstas las regu. lan -o pueden ser reguladas - por leyes más racionales. El típico ejemplo de este caso fué la investigación hecha por los tribunales ingleses a la Holding Company J. \& P. Coats, junto con sus diversas subsidiarias. Este block producía el $80 \%$. de hilo de coser usado en la Gran Bretaña, y una buena proporción del usado en el mundo. El ejemplo lo tomamos de "Monopolio" del economista de Cambridge, E. A. G. Robinson. Es un poco largo pero da una clave para patta de las ventajas que se pueden obtener para el públicó y para los empresarios a través de la Holding Company. "Una comisión establecida por la Ley de Ganancias Ilícitas - dictada por el Gobierno británi. co en 1919 y 1920 - presentó tres informes sobre las actividades de la em. presa Coats. No nos interesan aquí los problemas en que se ocupó predominantemente dicha Comisión, o sea los del precio del carrete de hilo y la cuestión de si el margen de la ganancia se calculaba correctamente teniendo en cuenta el precio efectivo pagado por el algodón o el precio del momento en el mercado abierto. Lo que nos atañe es responder a la pregunta siguiente: ¿por qué si, como afirmaban algunos de los miembros de la Comisión, el margen era en realidad excesivo, no ingresaban nuevos competidores a la industria? Esto se explicaba, en parte, por la existencia de un acuerdo especial entre la agencia central de ventas y la Cámara de Comercio de Paños, según el cual los manufactureros de paño estaban obligados, bajo pena de que se cancelaran sus créditos, a cobrar el mismo porcentaje de ganan. cias sobre el algodón de los competidores que sobre el de la casa Coats. Parece que este acuerdo entró en vigor a petición de los fabricantes de paño y con objeto de impedir rebajas del precio, pero de hecho constituyó un obstáculo para los posibles competidores. Sin embargo, mucho más importancia tuvo la ventaja obtenida por la casa Coats en sus costos de manufacturas, ventaja tanto más sorprendente cuanto que apenas la tercera parte del hilo que empleaba se hilaba. La primera Comisión informó que aún cuando el precio se elevara considerablemente por encima del nivel $7 \mathrm{r} / 2$ peniques el carrete que entonces prevalecía, la empresa Coats todavia podría vender una proporción muy grande de su producción, debido, en su mayor parte, a que su cuantioso capital le permitía adquirir las materias primas en el momen. to más propicio; a que poseía una organización muy especializada y a que su sección de hilados era muy eficiente. Uno de los principales competido. res de la Coats informó a la Comisión "que no podía fabricar hilo de coser de seis cuerdas a un precio que dejara un margen moderado de ganancia para él o el almacenista si el carrete se vendía a menos de un chelín cada uno, en contraste con el precio de $71 / 4$ que valía el hilo de coser de Coats". Desde luego que esto se debía en parte, a que Coats había corrido el riesgo de adquirir por anticipado fuertes cantidades del algodón y a que habia tenido la suerte de poseer materia prima barata cuando el mercado del hilo de coser 
estaba en alza; pero se debia aún más a sus considerables economias en la producción.

Estos mejores precios en infinidad de artículos, han hecho posible que muchos de los que se consideraron de lujo hacen pocos años, sean hoy considerados al alcance de todos los bolsillos. I o mismo con productos farmacéuticos, y de éstos el ejemplo más reciente, la penicilina, la mágica $y$ dificil droga, tan complicada y morosa en su producción, tan restringida en su consumo. Hoy, gracias a los grandes sindicatos droguísticos de los E.E. U.U. y del Reino Unido, en el transcurso de dos años, la penicilina está al alcance de todos, y sino el Decreto dictado por nuestro Gobierno (Junio 1945) por el que se permite la venta de tal droga con sólo la receta de médico. La lista sería interminable, y es por esta circunstancia que muchas veces se ha encontrado que el querer impedir el funcionamiento de la Holding perjudica a la comunidad.

Importante posición tienen en los Estados Unidos de América y en la Argentina. Las consecuencias-son beneficiosas para el Estado y para la co. munidad en forma directa, puesto que es premisa conocida que el Estado es el peor y más caro administrador de cualquier empresa.

Es interesante transcribir a este respecto la opinión del famoso político y financiero norteamericano, Mr. Wendell L. Wilkie, pronunciada en una conferencia dictada en el "Economic Club of New York", en Enero de 1935, y notable por la posición que tomaba, decía que la expansión de las Holding Companies, que permitieron reunir capitales y personal técnico requerido para emprender obra de tal magnitud, que hizo posible dotar a los Estados Unicos de un eficiente y bien organizado servicio de electricidad. Y al referirse al sentimiento de oposición de algunos funcionarios contra las Holding Companies expresa: "Aquellos que se oponen a la organización de estas empresas, asumen postura de virtud y patriotismo superior. Tratan de pintar a los que representan las empresas de servicios públicos, como seres antisociales, sin patriotismo y como explotadores de la Humanidad. No me gus. ta hacer referencias personales, pero debo decir que ningún deber que se me ha presentado en mi vida, aún en el servicio de mi patria, que tanto haya apelado a mi sentido de obligación social, patriotismo y amor a la humanidad, como este: mi obligación de decir y hacer lo que yo pueda en favor de la conservación de empresas privadas que explotan servicios públicos".

"Todo lo que he podido observar, todo lo que sé y todo lo que leo, me inducen a creer que no podría hacer nada más noble para la estabilidad económica del futuro, para el bien político de mi patria o para el bienestar social y económico de mis conciudadanos, que el mantenerme firme y sin temores contra este ridículo capricho y antojo del momento".

Como podrá verse la valiosa opinión de este político, conocido en el mundo por su franqueza y por su sinceridad ideológica, que sin ambajes está de acuerdo con el punto de vista de lo conveniente que, para el Estado y los ciudadanos, es la explotación de los servicios públicos por empresas particulares, por las Holding Companies.

\section{INCONVENIENTES:}

Todas las instituciones humanas, por buenas que sean, tienen sus inconvenientes, y estos también se presentan en las Holding Companies. Los más importantes trataremos de enumerarlos, pero insistimos en las dificultades que se presentan para localizarlos e individualizarlos; y cuán sujetas están 
las cosas humanas a tantas contingencias. En nuestra opinión, los principales inconvenientes son:

a).-Abusos de carácter bolsístico.-Valorizar los capitales de las Compañias que se incorporan al Holding, en tal forma, que se pueden vender al público las acciones por precios superiores a los reales.

b).-De carácter tributario.-Las mayores posibilidades que existen para las Holding Companies, gracias a la extensión de sus operaciones - sin tener en cuenta sus técnicos contables e influencias- para burlar la tributación. Un ejemplo simple de la burla de impuestos se tiene, en que con una inteligente desdoblación de capitales, por medio de Compañías; de hábiles juegos con repartición de pérdidas, etc., etc., se consiguen maravillosas evasiones tributarias mediante la forma de presentar el capital imponible, con lo cual se obtienen apreciables descuentos por conseguir favorables tipos en las tasas progresivas.

También burlan los impuestos fijando valores excesivos a materiales o servicios prestados por las empresas asociadas. En gran número de las constituciones de las Holding Companies la gran aspiración es la evasión fiscal.

c).-De carácter político_social.-La Holding Company que domina monopolísticamente una industria tiene fuerza para imponer sus condiciones, y éstas aceptadas, por ser servidores. Pongamos por ejemplo: Una Holding Company que domine la industria pesquera, poseyendo embarcaciones, astilleros, fábricas de redes, hilos para las mismas, etc., etc., seria "se. ñora de horca y cuchillo" de todos los pescadores.

d).--De orden económico-político.-La elevación artificial de precios, en detrimento de los consumidores. La base en que fundamenta su adversión a las Holdings el notable economista francés Charles Gide es de opinión de que: "la Holding Company es una forma de monopolio destinada a do. minar el mercado y fijar abusivamente los precios.

e).-De carácter moral-comercial.-Para obtener el éxito en muchas Holdings no ha sido extraño el usar de los medios de competencia desleal. Estudiar estos difíciles problemas es complicado. De todas maneras citaremos algunos típicos ejemplos: la rebaja de precios en un determinado sector - sostenido por las ganancias de otros sectores-. destinados a matar una empresa local con pocos medios económicos y con fines de absorción; los cohechos dentro del personal de otras empresas reacias a la asocia. ción, etc., etc. Esta competencia desleal ha adquirido extremos insospechables y es muy difícil de reprimir por su complejidad.

Todos estos inconvenientes no son exactamente originados por las Holding Companies, sino que son el resultado de la competencia comercial actual, pero en cambio son fáciles de suprimir por medio de una legislación adecuada y con la creación de organismos técnicos de control bien organizados y dotados de personal eficiente $y$ honesto.

Cuanta mayor sea la concentración más fácil será la fiscalización de las operaciones que se realizan. La dispersión de compañías y empresas com. plica el control a ejercerse por el Estado.

El Holding en sí es una forma eficiente. El mal o el bien de la Holding está en relación directa con su finalidad.

Prohibir el funcionamiento de las Holding Companies dentro de nues. tra actual organización legal, económica, técnica, financiera, etc., sería una aberración. Es indispensable permitir la vida de las Holding Companies, cuidando, es lógico, de reglamentarlas con eficiencia y sin que tales regla- 
mentaciones alteren su propia naturaleza y destruyan su poderosa acción constructiva.

Un rápido examen del desarrollo industrial y económico de los grandes centros de producción, permiten afirmar que los sindicatos, corporaciones, trusts, carteles, "combinations", etc. y particularmente las Holding Companies, a pesar de sus inconvenientes, han desempeñado papel importantisimo en el desenvolvimiento humano.

\section{LIBERTAD DE ASOCIACION CON FINES COMERCIALES Y EL PRINCIPIO DE RAZONABILIDAD}

El espíritu de nuestro Código de Comercio en lo referente a Sociedades $y$ formas de asociación con fines comerciales es sumamente liberal, dando por lo tanto la más amplia libertad.

La libertad de formas queda establecida en el artículo 125, que dice: "El contrato mercantil celebrado con los requisitos esenciales del derecho, será válido y obligatorio entre los que lo celebren, cualesquiera que sea la forma, condiciones y combinaciones lícitas y honestas que lo constituyan", siempre que no estén expresamente prohibidas en nuestro Código.

El artículo 126 completa el espíritu del anterior, al dar libertad de contratación para las compañias mercantiles y terceros, cuando dice: "Serán igualmente válidos y eficaces los contratos entre las compañías mercantiles y cualesquiera persona capaces de obligarse, siempre que fueren lícitos y honestos, y aparecieren cumplidos los requisitos que se exepra en el artículo siguiente".

El artículo 127 consigna los siguientes requisitos necesarios para los contratos de constitución de compañías mercantiles; pero éstos se refieren en forma especial a las șolemnidades y publicidad de que se les debe rodear. Estos requsitos se ven en el articulado del Título $\mathrm{I}$, de la Sección $\mathrm{I}$, del $\mathrm{Li}$ bro II del Código de Comercio, que se intitula: "De la constitución de las compañías y sus clases". Estos requisitos son eminentemente formalistas y no se deben confundir ni con los requisitos exigibles para la adquisición de la capacidad jurídica ni con los que demanda la constitución social de una compañía.

La libertad concedida para la asociación comercial a través del articulado del Código de Comercio se ve razonada en su Exposición de Motivos: "Como consecuencia de los dos primeros principios (que son los de libertad de asociación y la no oposición a los principios del Derecho y la Moral), se declara válido todo contrato de compañia mercantil, cualesquiera que sean las formas y combinaciones que se estipulen, siempre que sean lícitas $\$$ honestas, o no estén expresamente prohibidas por el Derecho. Se declara así mismo libre la constitución y creación de toda clase de asociaciones mercantiles..."

Desgraciadamente, $y$ digo así porque no se ha ido a resolver problemas de interés sino de carácter formal, en la práctica se ha hecho una interpretación, a mi parecer, errónea del artículo 130 de nuestro Código de Comercio. Erradamente se ha interpretado este artículo en forma restrictiva, $y$ por esta razón en el Registro Mercantil no se acepta la inscripción como sociedad comercial a la de "Responsabilidad Limitada", dado que la interpretación festrictiva ha llevado a tomar como enumeración taxativa a la que hace el 
articulo referido, cuando por su texto se ve que es una simple enumeración enunciativa o demostrativa, al expresar: "POR REGLA GENERAL, las compañías mercantiles se constituyen adoptando alguna de las siguientes formas....", y pasa a enumerar las tres clásicas sociedades, sin pretender que todas las compañías mercantiles se organicen para regirse dentro de las tres formas enunciadas, que son: Colectiva, Comanditaria y Anónima.

Los dispositivos legales mencionados y las citas tomadas de la "Exposición de Motivos", nos demuestran que el principio de libertad de asociación es el aceptado por nuestro Cócigo de Comercio, y en la forma más amplia. Este espíritu liberal no es extraño en la legislación comercial, pues así trata de estar al día con los adelantos del comercio y sus necesidades, pudiendo crearse, sin oposieión legal los elementos que le sean necesarios, siempre y cuando no se opongan a los principios de Derecho Natural a los de la Moral. De acuerdo con lo expuesto, encontramos en la Exposición de Motivos el siguiente párrafo: "Era necesario que una ley determinase los principios, INSPIRADA EN EL MAS ABSOLUTO RESPETO AL PRINCIPIO DE LA LIBERTAD DE ASOCIACION, sin trabas ni fiscalizaciones de ninguna especie, que estableciere como única garantía para los derechos de los terceros la publicidad; y en la que cupieren dentro de sus an. chos moldes y de su expansivo espiritu, CUANTAS COMBINACIONES PUEDA CONCEBIR LA ACTIVIDAD HUMANA ACERCA DEL DERECHO DE ASOCIACION. SIEMPRE QUE SEAN LICITAS Y HONESTAS Y NO SE OPONGAN A LOS PRINCIPIOS DEL DERECHO NATURAL Y A LOS PRINCIPIOS DE LA MORAL.

Después de las citas hechas, obvio y redundante resulta decir que las Holding Companies pueden funcionar legalmente en nuestro país. De he cho en el Perú funcionan y existen constituciones sociales en las cuales se expresa como finalidad la de las Holding Companies. Razones de discreción me impiden dar ejemplos que conozco.

Establecido que las Holding Companies pueden funcionar, porque positivamente funcionan, $y$ porque existe la libertad de asociación; cabria ha-

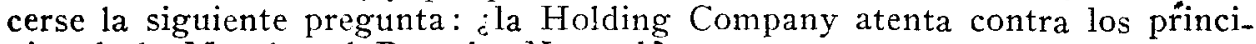
pios de la Moral y el Derecho Natural?

La solución de esta interrogante debe ser alcanzada a través de un criterio de buena fe, de sentido común, de "razonabilidad" (nuevo término creado para expresar el concepto que tratamos de aclarar). Este nuevo concepto entra a ocupar un papel importante dentro del derecho moderno. Ahora bien no constituye, claro está, una norma escrita; sino que fluye del lógico sentido que debe primar en las relaciones juridicas.

El principio de razonabilidad ha adquirido gran importancia en los novísimos tratadistas del Derecho y sirve para racionalizar la ley, quitándole esa fría y ciega rigidez. Con este principio no hay necesidad de artilugios bizantinos para explicar hechos simples. Así por ejemplo, dentro de la fría rigidez del FREE TRADE se debe aceptar cualquier combinación comercial, cualesquiera que sean sus fines, por que no ofende el principio del "Free Trade". La razonabilidad, con amplio criterio se ve que la ley tiene deter. minados límites en derechos innatos que no pueden -así no estén escritos por evidentes - ser transgredidos por ley o principio humano alguno porque sería ir contra la naturaleza del hombre.

En el Perú, tanto en nuestro Código Civil como en el Código de Comercio encontramos, implícitamente por cierto, este principio de razonabilidad. 
Así muchas veces las disposiciones contenidas en el Título Preliminar del Código Civil son de pura "razonabilidad". Verbigracia el artículo II: "La ley no ampara el abuso del derecho".

Son de razonabilidad pura las limitaciones que señala a la libertad de asociación el Código de Comercio en su Exposición de Motivos: "SIEMPLE QUE SEAN LICITAS Y HONESTAS" o el de no estar "OPUESTOS A LOS PRINCIPIOS DEL DERECHO NATURAL Y A LA MORAL". Del mismo carácter, las mismas palabras literales usa el Código en el artículo 126: "serán igualmente válidos y eficaces los contratos entre compañías... SIEMPRE QUE FUEREN LICITOS Y HONESTOS”.

El principio de razonabilidad está en el Derecho Natural, en la licitud misma del derecho que fija la ley positiva.

De acuerdo pues con nuestro Código de Comercio, la Compañía Tenedora $\mathbf{u}$ Holding Company puede funcionar, porque positivamente pueden funcionar por el principio de libertad de asociación establecido, y negativamente, porque la razonabilidad prueba su licitud. Fundamentar la licitud de la Holding Company seria repetir argumentos expuestos en el anterior capítulo.

\section{CONCLUSIONES :}

Las conclusiones de esta tesis se van derivando a través de sus capitulos, por no decir a través de cada una de sus páginas, pero trataré de señalar, en mi opinión, las más importantes:

1.-La Holding Company consiste en la asociación de varias empresas, bajo una rectora y coordinadora, dentro de la cual conservan una relativa independencia de orden técnico y económico.

$2^{\circ}$.- La Sociedad Anónima es el principal instrumento jurídico de la Holding Company.

$3^{\circ}$.- La Holding Company es un poderoso factor de expansión económica que ha contribuido y contribuye al mejoramiento de los procesos económicos de producción, distribución y consumo de bienes.

$4^{\circ}$.- Por sus especiales características difiere, a pesar de tener grandes similitudes, con el POOL que sólo busca la limitación de la producción; con el KARTELL que va a uniformar las condiciones de venta de un grupo de empresas; y con el TRUST, porque en este sistema las asociadas pierden su autonomía por el "fideicomiso".

Los fines que persigue la Holding Company son: mejorar a través de una racionalización de esfuerzos económicos todos los aspectos o ciclos de la economía, o sea intervenir en todo el proceso económico.

59.-Desde el punto de vista económico-legal clásico, la unión de empresas, era odiosa e ilícita porque se tenía el pre-concepto de que el JUSTO PRECIO se obtenía por la libérrima concurrencia, y por ende malo todo lo que artificialmente la alterase, y que por cierto que lo alteran las uniones de empresas al impedir o trabajar, ya sea directa o indirectamente, la competencia.

Este principio ha sido abandonado, cuando menos parcialmente, al comprobarse que la libre concurrencia absoluta podía ocasionar terribles perjuicios a las industrias, las que podían, como de hecho lo hicieron, traer hondas conmociones sociales. Por esto no se puede juzgar a priori si una asociación es o no lícita, aunque lleve al ejercicio del monopolio. Su aprobación y su condena estarán sujetas a lo que representen para el bien común. Las más modernas legislaciones contemplan estos casos. 
69.-La Holding Company bien controlada llena una función de mejoramiento social, al conducir al abaratamiento de los artículos que produce o en que trabaja. Al producirse este abaratamiento se producen los mejoramientos del "standard" de vida, pues como señalábamos, el artículo de lujo se torna en artículo al alcance de cualquier bolsillo.

$7^{9}$.-La Holding Company, dentro del concepto de razonabilidad no atenta, necesaria o intrínsecamente, contra la libertad de comercio. La Supreme Court of Justice de los Estados Unidos así lo declaró, entendien. do que se tenía que estudiar si existia o no una "unreasonable restriction of competive condition".

$8^{\circ}$.-Las legislaciones deben propender no a prohibir, ni a reglamentar propiamente, sino a vigilar y controlar la marcha de las Holding Companies; teniendo muy presente que sus fines no sean contra los principios de la Eco. nomía, del Derecho y de la Sociedad. Para esto se hacen recomendables las comisiones de técnicos, y faltando éstos se hace casi imposible la vigilancia, pues la buena voluntad de los encargados será burlada por los expertós que nunca faltan a las grandes instituciones y menos a las Holdings.

$9^{\circ}$.- Las Holding Companies llenan una gran función al hacerse cargo de los servicios más eficientemente, tanto para el público en general como para el Estado, ya que es sabido que éste siempre perderá y hará perder cuando trata de explotar un servicio como negocio, y si no que lo digan los fe. rrocarriles peruanos. Dentro de la actual organización capitalista. prohibir o entorpecer el desarrollo de las Holding Companies es una aberración. Conforme a lo ya expresado, debe el Estado pernutir, y aún en el criterio de al. gunos tratadistas fomentar, su desenvolvimiento dentro de las normas jurídicas convenientes.

10 . - La moralidad y licitud de la Holding Company no es de carácter intrínseco, pues ella en sí es lícita. La ilicitud podría devenir de finalidades contrarias a la ley o a las buenas costumbres comerciales o sociales.

$11^{\circ}$.- - Las Holding Companies pueden funcionar en nuestra patria por permitirlo el Código de Comercio al establecer la legalidad del principio de "libertad de asociación" irrestricta. Funcionan dentro de los dispositivos legales de nuestro cuerpo de leyes comerciales la "razonabilidad", ya que como dijimos toda asociación es buena mientras no vaya contra el "Derecho Natural y la Moral". 


\section{B I B L I O G R A F I A}

\section{LEGISLACION CONSULTADA}

Código de Comercio.-Edición Oficial.

Código de Comercio.-M. A. de la Lama (Comentarios y con la "Exposi. ción de Motivos" y Apéndices).

Código Civil._Edición Oficial.

Código de Comercio de España.-Edición Oficial.

Códigos de la República Argentina--Edición Oficial.

Códigos de la. República de Chile.-Edición Oficial.

Códigos de la República Oriental del Uruguay.-Edición Oficial.

Company Laws.-Palmer, Francis B.-New York.

Anuario de la Legislación Peruana.-Edición Oficial.

\section{OBRAS CONSULTADAS :}

Benham, Frederic.-Curso Superior de Economía.-Barcelona.

Boninsegni.-Manuel elementaire d'economie politique.-Lausanne.

Castillo, R. S.--Sociedades Comerciales.

Cornejo, Lino--Derecho Comercial (Sociedades).-Lima.

Eckehard.-Cuatro Años de Gobierno de Hitler.-Santiago.

Elliot, Charles B.-A teatrise on the law of private Corporation revised by S. Chaplin.-Chicago.

Flechter.-Cyclopedia Corporation.-New York.

Gide, Charles.-Curso de Economía Política.-Buenos Aires.

Heinsheimer, Karl.-Derecho Mercantil.-Barcelona.

Kleinwachter, F. v.-Economía Política.-Barcelona.

Fernand Laurent.-Esquise d'un etude des legislation francaise et britannique en matiere de sociétés anonymes.-París.

León Montalbán, A.-Derecho Comercial-_ler. Curso.-Lima.

Lenín, V.-Obras Escogidas ( $1^{\circ}$ y $2^{\circ}$ Tomo)-Moscú.

Levy, H.-Industrial Germany.-New York.

List, F.-Economía Nacional--México.

Malarriga, C.-Código de Comercio Comentado.

Manzano, Bonilla y Miñana.-Derecho Mercantil-Barcelona.

Marshall, A.-Industry and Trade-Cambridge.

Mussolini, Benito.-Fascismo y Corporativismo.-Salamanca.

Ochoa y González.-Principios Económicos.--La Habana.

Over Laborde, Aser.-Sociedades de Responsabilidad Limitada.-Buenos Aires.

Plant, A.-Report of Committee on Trust.

J. Reyes Heroles.-Tendencias actuales del Estado.-México.

Rivarola, M. A.-Sociedades Anónimas.-Buenos Aires.

Robertson, D. H.-Industria.-México.

Robinion, E. A. G.-Monopolio--México.

Sombart, Werner.-El moderno Capitalismo.-Barcelona.

Stalín, J-Cuestiones del Leninismo.-Moscú.

Vivante, Cesare.-Traite de Droit Commercial.-Paris.

Vivante, Césare.-The Harvard Bussiness School Club (1935).

Vidari, Ercole.-Corso di Diritto Comercciale.-Roma.

Weber, Max.-Historia Económica General.-México. 